\title{
Competition and Innovation: Revisiting the Inverted-U Relationship
}

\author{
Michael Peneder
}

Received: 8 December 2011 / Revised: 14 December 2011

Accepted: 15 December 2011 / Published online: 20 January 2012

(C) Springer Science+Business Media, LLC 2012

\section{JEL classification $\mathrm{L} 11 \cdot \mathrm{L} 22 \cdot \mathrm{L} 41 \cdot \mathrm{M} 13 \cdot \mathrm{O} 33$}

This issue of the Journal of Industry, Competition, and Trade warrants some explanation in terms of a brief editorial. It presents a collection of papers that were independently submitted, but are closely related by their common interest in the question of how competition affects innovation. It is therefore not a special issue in the usual sense of an exclusive collection of invited papers, but an unusually focused issue on the topic of competition and innovation. It became possible only by an astonishing surge of renewed interest and novel research in this field.

What explains the sudden explosion of new papers on a topic that has been written about so often and for so long? We have already too many papers with too many conflicting findings available, some people (editors among them) might say. In contrast, we believe that this is a good time to revisit the relationship and consider the current stream of publications to be only the beginning of a new wave of research. Our optimism is not only based on the fact that both innovation and competition are two major ingredients in any modern approach to industrial policy, ${ }^{1}$ but also on the recognition of three powerful sources that offer new inspiration and opportunities that will continue to energize this development for some time to come.

First of all, there has been a remarkable shift in the guiding theoretical hypotheses. For decades the debate was dominated by the simplistic and apparently misguided antagonism between a negative 'Schumpeter effect' versus a positive 'Arrow effect' of competition on innovation. It was simplistic by assuming that the specific arguments presented either by Schumpeter $(1911,1942)$ or Arrow (1962) are linear and thus apply independently of the initial degree of competition in the market. It was also misguided in two ways. First, by ignoring that Schumpeter's postulate of the logical impossibility of endogenous innovation

${ }^{1}$ See, e.g., Aiginger (2007) on industrial policy.

M. Peneder $(\bowtie)$

Austrian Institute of Economic Research (WIFO), Arsenal Obj. 20, 1030 Vienna, Austria

e-mail: michael.peneder@wifo.ac.at 
within a market of perfect competition is strictly valid only at very high-levels of initial competition. And second, by ignoring that Arrow's positive impact of competition on innovation, which was derived from contrasting a legally protected monopoly with a competitive duopoly, is strictly valid only at a very low level of initial competition. As a consequence, the different incentives explained by Schumpeter and Arrow apply exactly at the opposite ends of the possible initial states of competition. Neither claimed his argument to prevail monotonically over the whole range of potential degrees of competition. Moreover, when Schumpeter talked about market power, he was interested in contested monopoly, where rivals compete for temporary monopoly profits from innovation, a situation which Arrow (1962, p. 619) considered to be "more nearly competitive than monopolistic".

Modelling the relationship between competition and innovation within the framework of Schumpeterian growth, Aghion et al. (2005) have championed an influential 'new' hypothesis, known as the inverted- $U$ relationship. In short, if the initial degree of competition is low, the inverted-U predicts a positive impact of rising competition on innovation effort. Conversely, at high levels of initial rivalry, increasing competition reduces the incentives for innovation. Apart from its technical sophistication, the nonlinear model also has much intuitive appeal, not the least because it can reconcile the arguments of both Arrow and Schumpeter. Taken together, the papers collected in this issue attest to the powerful inspiration which the Aghion et al. (2005) model provides to the new literature. All of them give it their due credit, and each of the empirical papers actually aims to test its core predictions.

The second major impetus for the new wave of empirical papers stems from the growing availability of micro-level data to the research community. This issue of JICT benefits in particular from the generous support by Charles Berubé and colleagues, who co-ordinated an ambitious research programme under the auspices of the OECD Working Party on Industry Analysis. We included three papers that are of particular interest. Each of them follows a joint research design to study a comprehensive national set of firm-level data, demonstrating the strong stimulus provided by the improved access to such data for this new stream of research.

Finally, the current wave of empirical research has been further fueled by the development of new measures of competition. Using traditional indicators, such as market concentration or price cost margins, has already caused big frustration to many researchers. Measures of supplier concentration suffer in particular from the difficulty to draw appropriate boundaries between different markets. ${ }^{2}$ On the one hand, most firms within the same industry classification do not compete for the same businesses. Typically, heterogenous firms specialize on different products and services, quality segments, or geographic areas, even if they belong to the same industry classification at very low levels of aggregation. On the other hand, in most cases competition through imports from suppliers abroad is not considered. ${ }^{3}$ The same deficiencies do not affect price-cost margins, which is the second major measure of competition traditionally used. However, Boone (2008a, b) has demonstrated that price-cost margins often tend not to be monotonous in competition. As an alternative, he proposed the profit elasticity index, which captures the sensitivity of profits to changes in cost. The rationale is based on the idea that in more competitive markets cost increases have a greater impact on the firm's profits than when competition is low. Among the articles presented in this issue, all the three empirical studies apply Boone's Profit

\footnotetext{
${ }^{2}$ See, e.g., Geroski (2003) for a discussion about how to define markets appropriately.

${ }^{3}$ Though one can, of course, calculate trade corrected measures of market concentration (e.g., Hölzl and Reinstaller 2009).
} 
Elasticity index to test the impact of competition on innovation. Again, they illustrate the powerful impulse for new research coming from innovations in measurement.

To briefly recapitulate the individual contributions to this issue, De Bondt and Vandekerckhove (2012) start with a selective survey of the theoretical literature, modestly titled "some reflections on the relation between competition and innovation". The modesty is owed to the great number, variety and complexity of models now available, which renders a comprehensive coverage almost impossible. Instead, the authors aim to provide the reader with a basic understanding of the seminal theories, grouping them by characteristic modelling strategies, and explaining the sensitivity of outcomes to the underlying assumptions. Among many other insights, they remind us that contrary to popular perception Aghion et al. (2005) were not the first to provide an analytic model of the inverted- $U$ relationship. Instead, they point to the work by Kamien and Schwartz (1976), which has not yet earned its due recognition in the current stream of literature.

The second paper is an original theoretic contribution by Felisberto (2012), titled "the relationship between competition and incumbent's innovation". It extends the comparison of innovation incentives under monopoly vs duopoly by a focus on the liberalization of formerly public network industries, where regulation may impose deviations from pure profit maximization. Calibrating the model for French postal services as an example (with similar calculations done for three other European countries), the price elasticity of demand for the incumbent is shown to have a consistently negative impact on innovation effort. In the duopoly case the model also depicts an inverted- $U$ relationship between the incumbent's market share and incentives for innovation. Due to economies of scale monopoly tends to exhibit higher incentives for cost reducing innovations. But depending on the incumbent's market share and elasticities of demand, there also exists an interval where investment in innovation under duopoly is larger than under monopoly. Finally, Felisberto investigates the incentives for cost reducing innovation conditional on the firm's objective function. They are shown to be lowest in the case of pure profit maximization, increase if the aim is to maximize revenues, and are highest when regulation can impose welfare objectives, e.g. by enforcing price caps.

The third paper, titled "market incentives for business innovation: results from Canada" is by Berubé et al. (2012). It opens the trilogy of empirical studies from the aforementioned OECD initiative. Like the two other studies, it is based on privileged access to extensive micro-data sets. In this case, the data are compiled from Statistics Canada's General Business Panel Survey initiative, which linked five administrative and survey datasets. Applying firm and industry level price cost margins as well as Boone's profit elasticity index at the industry level, they report a consistent positive effect of rising competition on R\&D expenditures. For the profit elasticity measure, adding a quadratic term leads to a significant negative coefficient, which would be consistent with the inverted-U relationship. However, the relationship disappears if price cost margins are used or a measure of the average distance-to-frontier is added. Estimating the model without a quadratic term, a larger technology gap reduces the investments in $\mathrm{R} \& \mathrm{D}$, implying that resources are more efficiently spent on technology adoption than on own innovation. Interacting the technology gap with the intensity of competition, the negative effect of the distance-to-frontier is reinforced by a growing intensity of competition.

The empirical section is complemented by a study on "competition and innovation in the Netherlands: testing the inverted-U for industries and firms" by Polder and Veldhuizen (2012). ${ }^{4}$ Offering a careful discussion of caveats regarding the inverted- $U$, they present

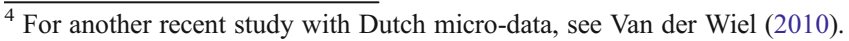


manifold reasons, both theoretical and empirical, why observed data might not display such a relationship. The empirical analysis is then based on a rich dataset sourced from various surveys by Statistics Netherlands. At the industry level, they find direct support for the inverted-U hypothesis, but only if Boone's profit elasticity is applied as measure of competition. Using the price cost margin does not produce significant results. For the micro-level analysis, only R\&D performers are kept in the sample and the quadratic term on competition is replaced by an interaction of technology spread and competition. Again they find a nonlinear relationship, where the marginal effect of competition turns from positive to negative as the technology spread within an industry increases.

The third empirical study on "competition and innovation in Luxembourg" by Peroni and Gomes Ferreira (2012) concludes the empirical section. It follows a largely analogous research approach with similar comprehensive firm and industry level data. But in contrast to the two previous papers, it does not support an inverted- $U$ relationship. The general impact of competition on innovation is negative, with a positive quadratic term in the nonlinear specification. The implied $U$ shaped relationship appears counter-intuitive, but finds some support in recent theoretic models, e.g. by Schmutzler (2010) or Tishler and Milstein (2009). Including a measure of the distance-to-frontier, the Boone profit elasticity index still has a negative impact, but that is reversed as the technology gap becomes smaller and industries are more efficient.

The following paper of de Almeida Costa and Barros (2012) is titled "does a tougher competition policy reduce or promote investment?" The authors think of a tougher competition policy in terms of either a higher probability of detection or an increase of fines. They distinguish between investments for own cost reduction on the one hand, and anticompetitive investments to raise the cost of rivals on the other. In both cases a tougher competition policy causes investments to decline. For own cost reductions the welfare effects depend on the investment parameters, whereas in the case of anti-competitive investments they are clearly positive.

The final paper "impact of horizontal mergers on research \& development and patenting: evidence from merger challenges in the U.S." by Park and Sonenshine (2012) investigates the impact of mergers on innovation. The authors use merger challenges to identify cases that were screened by authorities because of concerns about rising market concentration. Applying propensity score matching and a difference-in-differences method, they compare R\&D and patenting activities of challenged and non-challenged merger firms to a matched control group of non-merger firms. They find that the growth in $R \& D$ and patenting of challenged firms from the pre-merger to the post-merger periods was lower than that of nonmerged firms over the same period. In other words, only for those mergers that were challenged by antitrust authorities, firms showed a decline in post-merger innovation relative to the control group. Consequently, mergers are an impediment to innovation only in markets with already high levels of concentration.

Stimulated by recent developments in economic theory, data access, and measurement, the papers collected in this issue add important new pieces to the puzzle, bringing us closer to a consistent overall picture. Among the three theoretical contributions, the first takes stock of the literature and helps us to better understand the variety of models and their outcomes. The second paper extends the analysis to the case of former public monopolies, where regulation may enforce welfare goals instead of pure profit maximization. The final paper addresses the impact of a tougher competition policy on cost reducing investments, more generally. The three empirical papers add new evidence based on privileged access to large and comprehensive micro-data from national statistical offices. They generally support a non-monotonic relationship between competition and innovation, but the presumed 
inverted- $U$ is robust only to little variation in the specifications and the indicators used. Consequently, the authors acknowledge severe limitations in how they deal with the endogeneity of innovation and competition, which is due to the lack of suitable instrumental variables in their data. Clearly, this endogeneity problem will be among the most important areas of future research, where more attention must be given to the creation of structural models that one can relate to available data. ${ }^{5}$

\section{References}

Aghion P, Bloom N, Blundell R, Griffith R, Howitt P (2005) Competition and innovation: an inverted-U relationship. Quarterly Journal of Economics 120:701-728

Aiginger K (2007) Industrial policy: a dying breed or a re-emerging Phoenix. J Ind Compet Trade 7(3-4):297323

Arrow K (1962) Economic welfare and the allocation of resources for invention. In Nelson R (ed), The rate and direction of inventive activity. Princeton University Press, 609-626

Berubé C, Duhamel M, ErshovD (2012) Market incentives for business innovation: results from Canada. J Ind Compet Trade 12(1-2; this issue)

Boone J (2008a) Competition: theoretical paramaterizations and empirical measures. J Inst Theor Econ 164 (4):587-611

Boone J (2008b) A new way to measure competition. Econ J 118(531):1245-1261

De Almeida Costa AP, Barros PP (2012) Does a tougher competition policy reduce or promote investment? J Ind Compet Trade 12(1-2; this issue)

De Bondt R, Vandekerckhove J (2012) Reflections on the relation between competition and innovation. J Ind Compet Trade 12(1-2)

Felisberto C (2012) The relationship between competition and incumbent's innovation. J Ind Compet Trade 12 $(1-2$; this issue)

Geroski P (2003) Competition in markets and competition for markets. J Ind Compet Trade 3(3):151-166

Hölzl W, Reinstaller A (2009) Market structure: sector indicators. In: Peneder M (ed) Sectoral growth drivers and competitiveness of the European Union. European Communities, Luxembourg

Kamien MI, Schwartz NL (1976) On the degree of rivalry for maximum innovative activity. Quarterly Journal of Economics 90:245-260

Park WG, Sonenshine R (2012) Impact of horizontal mergers on research \& development and patenting: evidence from merger challenges in the U.S. J Ind Compet Trade 12(1-2; this issue)

Peneder M, Wörter M (2012) Competition, R\&D and innovation: testing the inverted-U in a simultaneous system. Mimeo, Vienna

Peroni C, Gomes Ferreira IS (2012) Competition and innovation in Luxembourg. J Ind Compet Trade 12(1-2; this issue)

Polder M, Veldhuizen E (2012) Innovation and competition in the Netherlands: testing the inverted U for industries and firms. J Ind Compet Trade 12(1-2; this issue)

Schmutzler A (2010) The relation between competition and innovation — why is it such a mess?, University of Zurich, Discussion Paper No. 0716

Schumpeter JA (1911) Theorie der wirtschaftlichen Entwicklung, 4th edn. Duncker \& Humblot, Berlin

Schumpeter JA (1942) Capitalism, socialism and democracy. Harper and Row, New York

Tishler A, Milstein I (2009) R\&D wars and the effects of innovation on the success and survivability of firms in oligopoly markets. International Journal of Industrial Organisation 27:519-531

Van der Wiel H (2010) Competition and innovation: Together a tricky rollercoaster for productivity. Tilburg University, Tilburg

\footnotetext{
${ }^{5}$ For example, Peneder and Wörter (2012) confirm a robust inverse- $U$ relationship by estimating a simultaneous system that follows from a relatively straightforward structural model.
} 